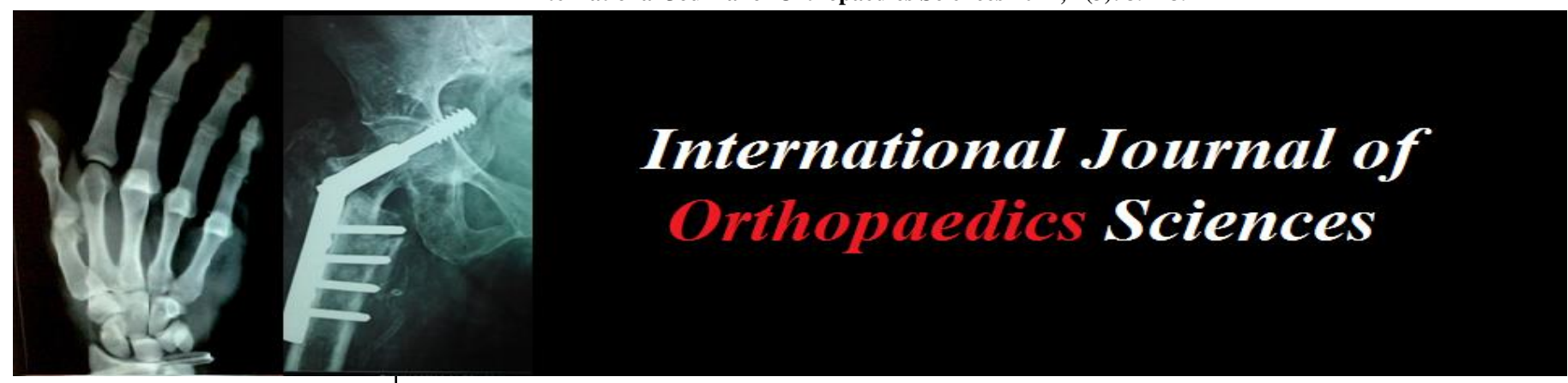

E-ISSN: 2395-1958

P-ISSN: 2706-6630

IJOS 2021; 7(3): 392-394

(C) 2021 IJOS

www.orthopaper.com

Received: 16-05-2021

Accepted: 18-06-2021

Dr. Umang Sanghvi

Assistant Professor, Department

of Orthopedics, Gujarat Adani

Institute of Medical Science,

Bhuj, Kutch, Gujarat, India

Dr. Dishant Bharatbhai Mehta

Resident Doctor, Department of Orthopedics, Gujarat Adani

Institute of Medical Science,

Bhuj, Kutch, Gujarat, India

Dr. Pranay Bhatt

First Year Resident Doctor, Department of Orthopedics, Gujarat Adani Institute of Medical Science, Bhuj, Kutch, Gujarat, India
Corresponding Author: Dr. Dishant Bharatbhai Mehta Resident Doctor, Department of Orthopedics, Gujarat Adani Institute of Medical Science, Bhuj, Kutch, Gujarat, India

\section{Prophylactic use of antibiotic coated intramedullary nail in open tibia fractures}

\author{
Dr. Umang Sanghvi, Dr. Dishant Bharatbhai Mehta and Dr. Pranay Bhatt
}

DOI: https://doi.org/10.22271/ortho.2021.v7.i3f.2777

\section{Abstract}

Background and Aim: Open fracture of tibia is one of the most common injuries seen in ortho pedic practice. The appropriate treatment of open tibial fractures is one of the priority problems in modern era of traumatology. Present study was done with an aim to assess functional and clinical outcome after intramedullary locking nail fixation of open fracture shaft of tibia.

Material and Methods: This prospective study was conducted in the Department of Orthopaedics, Gujarat Adani Institute of Medical Science, Bhuj, Kutch, Gujarat, India. 40 patients were treated over a period of 16 months with gentamicin coated tibia interlocking nail after taking written and informed consent. Antibiotic coated tibia interlocking nail with property of sustained release of gentamicin was used. The coating contains combination of gentamicin and biodegradable polymeric carrier Poly. An average size nail carries $100 \mathrm{mg}(1 \mathrm{mg} / \mathrm{cm} 2)$ gentamicin drug. Radiological Union was assessed using RUST Score and clinical assessment results were graded as excellent, good, fair and poor.

Results: The most common cause of injury was found to be due to road traffic accident. Fibula fracture was associated with $92.5 \%$ of patients. Time taken in wound healing in majority of patients was less than 5 weeks (45\%). Majority of patents $(47.5 \%)$ had RUST score 8 at six months of duration. Two cases got infected in this study and in one case there was non-union. Average duration of hospital stay was 15 days. Large numbers of patients had fair outcome $45 \%$.

Conclusion: In this study we showed that use of antibiotic coated nail to treat open tibial fracture was associated with an absence of deep wound infections. Antibiotic coated tibia interlocking nail is a good treatment option for open tibial fractures, yields good functional outcome with less complications in these fractures and should be used whenever indicated.

Keywords: antibiotic, fractures, gentamicin, tibia

\section{Introduction}

Tibia shaft fractures are the most common long-bone fractures among adults and children ${ }^{[1]}$. They have a deep socio-economic impact, accounting for approximately 26 fractures per 100,000 and 569,000 hospital days per year ${ }^{[1,2]}$. Men have a three times higher risk of fracture than women. Incidence increases in young adults who suffer high-energy trauma or in elderly people who suffer low-energy trauma directed towards poor quality bone tissue due to osteoporosis ${ }^{[3]}$. Incidence of nonunion in the general population is approximately $12 \%$ of all tibia fractures, and in open fractures this can raise up to $23 \%{ }^{[4]}$. Open tibia fractures account for two per 1000 injuries ${ }^{[5]}$. Open fracture of tibia is one of the most common injuries seen in orthopaedic practice. The appropriate treatment of open tibial fractures is one of the priority problems in modern era of traumatology. Tibia, being a subcutaneous bone, increases the chance of infection and nonunion. In choosing the optimal mode of treatment, one has to consider the importance of associated soft tissue injuries along with the configuration of fracture. Most of the orthopaedic trauma infections are caused by biofilm-forming bacteria ${ }^{[6]}$. Biofilm consists of hydrated matrix of polysaccharide and protein. Once formed, it protects the microorganism from antimicrobials, opsonization, and phagocytosis, thus contributing to the chronicity of infections ${ }^{[7]}$. In order to cure biofilm-related infection, four principles formulated by Cierny and Mader must be observed: (1) complete surgical debridement with dead space management, (2) fracture/nonunion stabilization, (3) soft tissue coverage, and (4) adequate antibiotic levels ${ }^{[8]}$. 
After using advance surgical techniques and antibiotics, there are chances of wound infection and osteomylitis. Gustilo grade III open fractures, rate of deep infection is about $80 \%$. According to other studies, on increasing grades of Gustilo the chances of infection increase. The effectiveness of systemic antibiotics is limited in reducing risk of infection with use of prosthesis and osteosynthetic devices $[9,10,11]$. Once implant gets infected, then it requires implant removal, debridement and long term antibiotic therapy. This implant related infection is prevented by delivering the antibiotics locally acting on tissue implant interface. One of such method is using a polylactic acid (PLA) coated intramedullary nail releasing gentamicin ${ }^{[8,11]}$. There are several studies showing reduction in implant related infection using antibiotic coated implants.

\section{Materials and Methods}

This prospective study was conducted in the Department of Orthopaedics, Gujarat Adani Institute of Medical Science, Bhuj, Kutch, Gujarat, India. 40 patients were treated over a period of 16 months with gentamicin coated tibia interlocking nail after taking written and informed consent.

\section{Inclusion criteria}

1. >18years of age.

2. Open fractures gustillo Anderson type 1, 2, 3A fracture.

\section{Exclusion criteria}

1. Associated with head injury.

2. Pathological fracture, fracture non-union and delayed union.

3. Patients not willing and medically unfit for surgery.

4. Patients who are pregnant, breast- feeding or planning to become pregnant during the study, a known allergy to aminoglycosides

Antibiotic coated tibia interlocking nail with property of sustained release of gentamicin was used. The coating contains combination of gentamicin and biodegradable polymeric carrier Poly. An average size nail carries $100 \mathrm{mg}(1$ $\mathrm{mg} / \mathrm{cm} 2$ ) gentamicin drug. After performing pre-anesthetic check-up, all patients were operated under spinal/epidural anesthesia. Patient was painted and sterile draping done. Knee flexed to $90 \mathrm{o}$ and entry point was made from the bare area over the tibial tuberosity under image intensifier. After passing the guide wire, serial reaming was done. Appropriate size of antibiotic coated nail measured and inserted into the medullary canal. I.V. antibiotics were given for 5 days postoperatively. Patient followed post-operatively at 1,2,3 and 6 months for outcome assessment.

\section{Statistical analysis}

The recorded data was compiled and entered in a spreadsheet computer program (Microsoft Excel 2007) and then exported to data editor page of SPSS version 15 (SPSS Inc., Chicago, Illinois, USA). For all tests, confidence level and level of significance were set at $95 \%$ and $5 \%$ respectively.

\section{Results}

All 40 patients (32 males and 8 females) were followed up for minimum of six months duration. The radiological Union was assessed using RUST Score (Table 1) and clinical assessment results were graded as excellent, good, fair and poor (Table 2 ). The study comprised $76.7 \%$ of the patients between $18-40$ years of age and $23.3 \%$ of the patients between $41-60$ years of age. In this study, there was predominance of male population. Males were $80 \%$ against females $20 \%$ (Table 1). The most common cause of injury was found to be due to road traffic accident. Fibula fracture was associated with $92.5 \%$ of patients. Time taken in wound healing in majority of patients was less than 5 weeks (45\%) (Table 2). Majority of patents $(47.5 \%)$ had RUST score 8 at six months of duration (Table 3). Two cases got infected in this study and in one case there was non-union. Average duration of hospital stay was 15 days. Large numbers of patients had fair outcome $45 \%$ (Table 4).

Table 1: Gender wise distribution of study participants

\begin{tabular}{|c|c|c|}
\hline Gender & Number & Percentage (\%) \\
\hline Male & 32 & 80 \\
\hline Female & 8 & 20 \\
\hline Total & 40 & 100 \\
\hline
\end{tabular}

Table 2: Time taken in wound healing

\begin{tabular}{|c|c|c|}
\hline Time taken in wound healing in weeks & Number & Percentage (\%) \\
\hline$\leq 5$ weeks & 18 & 45 \\
\hline 5-7 weeks & 12 & 30 \\
\hline 8-10 weeks & 6 & 15 \\
\hline Not healed & 4 & 10 \\
\hline Total & 40 & 100 \\
\hline
\end{tabular}

Table 3: Radiological union at six month (RUST score)

\begin{tabular}{|c|c|c|}
\hline $\begin{array}{c}\text { Radiological union at 6 month } \\
\text { (RUST score) }\end{array}$ & Number & Percentage (\%) \\
\hline 4 & 6 & 15 \\
\hline 8 & 19 & 47.5 \\
\hline 10 & 10 & 25 \\
\hline 12 & 5 & 12.5 \\
\hline Total & 40 & 100 \\
\hline
\end{tabular}

Table 4: Clinical outcome

\begin{tabular}{|c|c|c|}
\hline Functional outcome & Number & Percentage (\%) \\
\hline Excellent & 5 & 12.5 \\
\hline Good & 11 & 27.5 \\
\hline Fair & 18 & 45 \\
\hline Poor & 6 & 15 \\
\hline Total & 40 & 100 \\
\hline
\end{tabular}

\section{Discussion}

The treatment of infected nonunion requires procedures to control the infection and to provide stability in order to achieve union. ${ }^{11}$ There is no single universally accepted modality of treatment presently available for the management of infected nonunion. Traditionally, infected nonunions have been managed using two-step procedure to control the infection first and subsequently to treat the nonunion. Delivery of antibiotics to the infection site systemically or locally is essential in order to control infection. Long term infection and repeated debridement create excessive fibrosis around the nonunion site and hinder antibiotic permeability. ${ }^{12}$ Hence, delivery of antibiotics to the local site is far more beneficial than systemic administration of antibiotics. The use of antibiotic-impregnated polymethylmethacrylate cement beads for local delivery of antibiotics without any systemic toxicity has been well documented for the management of osteomyelitis and open fractures [13, 14]. However, these antibiotic cement beads do not provide any stability across fracture site and cannot be placed in the intramedullary canal as it entails difficult removal due to fibrous ingrowths. The antibiotics that are used for this purpose should have a broad 
spectrum of activity, should be heat stable, have good elution properties from the cement and should have low allergenicity. Most of the researchers in past used a combination of vancomycin with gentamicin or tobramycin ${ }^{[15,16,17]}$

This study comprised of 40 patients, out of them 20 patients had grade-I, 16 patients had grade-II and 4 patients had gradeIII compounding. In a study by Bhanu Pratap et al. ${ }^{[18]} 13$ $(52 \%)$ cases were of grade-I fractures and $12(48 \%)$ cases were others. In other study by Khaled Hamed et al. ${ }^{[19]}$ also exhibited eight $(72.72 \%)$ patients had Gustilo type I fracture while three $(27.27 \%)$ patients had type II fracture. Out of 40 patients, fracture union was achieved in 38 patients and only two patients patients undergone non-union. This was in accordance with the study of Bhanu Pratap et al. ${ }^{[18]}$. and Thomas Fuchs et al. ${ }^{[20]}$. where none of the patient undergone non-union. In a study of 25 patients by Bhanu Pratap et al. ${ }^{[18]}$. infection in two $(8.0 \%)$ patients were observed. In a similar study Thomas Fuchs et al. ${ }^{[20]}$ out of 19 patients noticed infection in only one $(5.26 \%)$ patient. These findings are consistent with the findings of our study where in a group of 40 patients, infection was found only in two patients. The average time taken by fracture to unite in various studies was around 9-24 weeks. Average time of wound healing in our study was 4.15 weeks.

\section{Conclusion}

Implant related infection pose an important challenge in the surgical treatment of tibia shaft fracture. Local administration of antibiotics might minimize the risk of infection. In this study we showed that use of antibiotic coated nail to treat open tibial fracture was associated with an absence of deep wound infections. Antibiotic coated tibia interlocking nail is a good treatment option for open tibial fractures, yields good functional outcome with less complications in these fractures and should be used whenever indicated. Randomized controlled trials with large sample size and longer duration of follow up are needed to devise a standard treatment protocol for management of open tibia fractures.

\section{References}

1. Schmidt AH, Finkemeier CG, Tornetta P. Treatment of closed tibial fractures. J. Bone Joint. Surg. Am 2003;85:352-368. [CrossRef]

2. Court-Brown CM, McBirnie J. The epidemiology of tibial fractures. J Bone Joint Surg Br 1995;77:417-421.

3. Weiss RJ, Montgomery SM, Ehlin A, Al Dabbagh Z, Stark A, Jansson KA. Decreasing incidence of tibial shaft fractures between 1998 and 2004: Information based on 10,627 Swedish inpatients. Acta Orthop 2008;79:526533. [CrossRef] [PubMed]

4. Antonova E, Le TK, Burge R, Mershon J. Tibia shaft fractures: Costly burden of nonunions. BMC Musculoskelet. Disord 2013;14:42. [CrossRef]

5. Behrens F, Searls K. External fixation of the tibia. Basic concepts and prospective evaluation. Bone Jt. J 1986;68:246-254. [CrossRef]

6. Court-Brown CM, Rimmer S, Prakash U, McQueen MM. The epidemiology of open long bone fractures. Inj 1998;29(7):529-34.

7. Court-Brown CM, Bugler KE, Clement ND, Duckworth AD, McQueen MM. The epidemiology of open fractures in adults. A 15- year review. Inj 2012;43(6):891-7.

8. Howard M. Epidemiology and management of open fractures of the lower limb. $\mathrm{Br} \mathrm{J}$ Hosp Med 1997;57(11):582-7.
9. Gaebler C, Berger U, Schandelmaier P, Greitbauer M, Schauwecker HH, Applegate B, et al. Rates and Odds Ratios for Complications in Closed and Open Tibial Fractures Treated With Unreamed, Small Diameter Tibial Nails: A Multicenter Analysis of 467 Cases. J Orthop Trauma 2001;15(6):415-23.

10. Diefenbeck M, Muckley T, Hofmann GO. Prophylaxis and treatment ". of implant-related infections by local application of antibiotics. Inj 2006;37(2):S95-S104. 11. Schmidmaier G, Wildemann B, Stemberger A, Haas NP, Raschke M. Biodegradable poly(D,L-lactide) coating of implants for continuous release of growth factors. J Biomed Mater Res 2001;58(4):449-55.

11. Thonse R, Conway J. Antibiotic cement-coated interlocking nail for the treatment of infected nonunions and segmental bone defects. J Orthop Trauma 2007;21:258-68.

12. Akinyoola AL, Adegbehingbe OO, Aboderin AO. Therapeutic decision in chronic osteomyelitis: Sinus track culture versus intraoperative bone culture. Arch Orthop Trauma Surg 2009;129:449-53.

13. Beals RK, Bryant RE. The treatment of chronic open osteomyelitis of the tibia in adults. Clin Orthop Relat Res 2005;433:212-7.

14. Henry SL, Ostermann PA, Seligson D. The prophylactic use of antibiotic impregnated beads in open fractures. J Trauma 1990;30:1231-8.

15. Paley D, Herzenberg JE. Intramedullary infections treated with antibiotic cement rods: Preliminary results in nine cases. J Orthop Trauma 2002;16:723-9.

16. Thonse R, Conway J. Antibiotic cement-coated interlocking nail for the treatment of infected nonunions and segmental bone defects. J Orthop Trauma 2007;21:258-68.

17. Dhanasekhar R, Jacob P, Francis J. Antibiotic cement impregnated nailing in the management of infected nonunion of femur and tibia. Kerala Journal of Orthopaedics 2013;26(2): 93-7.

18. Pratap B, Gaur A, Joshi V. Functional outcome of antibiotic coated interlocking intramedullary nail in open tibia diaphyseal fracture. Int J Orthop Sci 2019;5(2):8037.

19. Salem KH. Critical analysis of tibial fracture healing following unreamed nailing. Int Orthop 2012;36(7):14717.

20. Fuchs T, Stange R, Schmidmaier G, Raschke MJ. The use of gentamicin-coated nails in the tibia: preliminary results of a prospective study. Arch Orthop Trauma Surg 2011;131(10):1419-25. 